\title{
Aerosol assisted chemical vapour deposition of germanium thin films using organogermanium carboxylates as precursors and formation of germania films
}

\author{
ALPA Y SHAH, AMEY WADAWALE, VIJAYKUMAR S SAGORIA, VIMAL K JAIN*, \\ C A BETTY and S BHATTACHARYA ${ }^{\dagger}$ \\ Chemistry Division, ${ }^{\dagger}$ Technical Physics Division, Bhabha Atomic Research Centre, Mumbai 400 085, India
}

MS received 18 May 2011; revised 26 July 2011

\begin{abstract}
Diethyl germanium bis-picolinate, $\left[\mathrm{Et}_{2} \mathrm{Ge}\left(\mathrm{O}_{2} \mathrm{CC}_{5} \mathrm{H}_{4} \mathrm{~N}\right)_{2}\right]$, and trimethyl germanium quinaldate, $\left[\mathrm{Me}_{3} \mathrm{Ge}\left(\mathrm{O}_{2} \mathrm{CC}_{9} \mathrm{H}_{6} \mathrm{~N}\right)\right]$, have been used as precursors for deposition of thin films of germanium by aerosol assisted chemical vapour deposition (AACVD). The thermogravimetric analysis revealed complete volatilization of complexes under nitrogen atmosphere. Germanium thin films were deposited on silicon wafers at $700^{\circ} \mathrm{C}$ employing AACVD method. These films on oxidation under an oxygen atmosphere at $600^{\circ} \mathrm{C}$ yield $\mathrm{GeO}_{2}$. $\mathrm{Both}^{\mathrm{Ge}}$ and $\mathrm{GeO}_{2}$ films were characterized by XRD, SEM and EDS measurements. Their electrical properties were assessed by current-voltage $(I-V)$ characterization.
\end{abstract}

Keywords. Organogermanium; germanium thin films; AACVD; XRD.

\section{Introduction}

Germanium has gained a renewed interest in electronics industry due to its lower bandgap energy $(0.67 \mathrm{eV})$ and higher electron and hole mobilities than silicon (Sze et al 1981). Germanium based thin films find numerous applications in micro-electronic devices. Germanium oxide $\left(\mathrm{GeO}_{2}\right)$ is used as blue photoluminescent materials (Zacharias and Fauchet 1998; Trukhin 2009; Liu et al 2010), whereas $\mathrm{GeO}_{2}$ based glasses having high refractive index are used for nano connections in optoelectronic devices (Kim et al 2003).

Recently, several synthetic approaches have emerged to prepare germanium and germanium oxide nanocrystals and thin films. For the preparation of $\mathrm{GeO}_{2}$ nanocrystals, $\mathrm{Ge}(\mathrm{OR})_{4}\left(\mathrm{R}=\mathrm{Pr}^{\mathrm{i}}\right.$ or $\left.\mathrm{Bu}^{\mathrm{t}}\right)$ are frequently employed (Kim et al 2003; Shah et al 2010). Several strategies have been adopted for deposition of germanium thin films, among them CVD has emerged as a promising technique due to its versatility. The most commonly used germanium precursor is the pyrophoric germane $\left[\mathrm{GeH}_{4}\right]$ (Kohlhase et al 1991; Mukherjee et al 2001; Wang et al 2004). Organogermanium compounds like $\left[\mathrm{Cp}^{*} \mathrm{GeH}_{3}\right]$ (Dittmar et al 2001), $\left[\mathrm{Et}_{n} \mathrm{GeH}_{4-n}\right](n=1-4)$ (Pola et al 1992b), $\left[\mathrm{Bu}^{i} \mathrm{GeH}_{3}\right]$ (Woelk et al 2006), [Bu $\left.{ }^{i} \mathrm{GeCl}_{3}\right]$ (Woelk et al 2006), $\left[\mathrm{Me}_{3} \mathrm{GeCl}\right]$ (Woelk et al 2006), [ $\left.\mathrm{Et}_{4} \mathrm{Ge}\right]$ (Boucham et al 1998), $\left[\mathrm{Me}_{3} \mathrm{Ge}(\mathrm{OEt})\right]$ (Fajgar et al 1995), [(PhGeO$\left.\left.{ }_{1.5}\right)_{n}\right]$ (Henderson et al 2010) and cyclic germylene (Veprek et al 1996) have been employed as precursors in CVD methods. Tetramethoxy germane, $\left[\mathrm{Ge}(\mathrm{OMe})_{4}\right]$ (Pola et al 1992a;

\footnotetext{
*Author for correspondence (jainvk@barc.gov.in)
}

Henderson et al 2010), has been used for the preparation of organogermanium films by laser induced deposition. The compounds like $\left[\mathrm{Me}_{3} \mathrm{Ge}(\mathrm{OEt})\right]$ and $\left[\mathrm{Ge}(\mathrm{OMe})_{4}\right]$ give films contaminated with carbon, hydrogen and oxygen (Fajgar et al 1995), while the germanium hydride precursors are toxic and pyrophoric whereas chlorinated compounds are corrosive. To overcome these problems, research is directed to design and develop new organogermanium precursors for deposition of germanium films by CVD.

Recently, we have described the synthesis of organogermanium carboxylates and characterized some of them, $\left[\mathrm{Et}_{2} \mathrm{Ge}\left(\mathrm{O}_{2} \mathrm{CC}_{5} \mathrm{H}_{4} \mathrm{~N}\right)_{2}\right]$ (1) and $\left[\mathrm{Me}_{3} \mathrm{Ge}\left(\mathrm{O}_{2} \mathrm{CC}_{9} \mathrm{H}_{6} \mathrm{~N}\right)\right]$ (2), (scheme 1) by X-ray structural analyses (Shah et al 2009). It was considered worthwhile to examine their suitability as precursors for deposition of germanium thin films.

\section{Experimental}

Organogermanium carboxylates, $\left[\mathrm{Et}_{2} \mathrm{Ge}\left(\mathrm{O}_{2} \mathrm{CC}_{5} \mathrm{H}_{4} \mathrm{~N}\right)_{2}\right]$ (1) and $\left[\mathrm{Me}_{3} \mathrm{Ge}\left(\mathrm{O}_{2} \mathrm{CC}_{9} \mathrm{H}_{6} \mathrm{~N}\right)\right]$ (2) were synthesized by an earlier reported method (Shah et al 2009) and were characterized by NMR spectroscopy. Germanium thin films were deposited on $\mathrm{Si}$ substrate $(1 \times 1 \mathrm{~cm})$ by aerosol assisted chemical vapour deposition (AACVD). Single crystals of silicon wafers (thickness $380 \pm 30 \mu$; with (100) or (111) orientation, boron doped ( $p$-type) with resistivity 1-3 ohm-cm) were used for deposition of thin films. Prior to deposition, Si wafers were thoroughly cleaned by standard RCA cleaning procedure. Deposition was carried out on cleaned rough surface. 


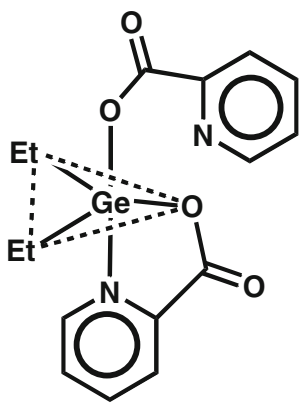

(1)

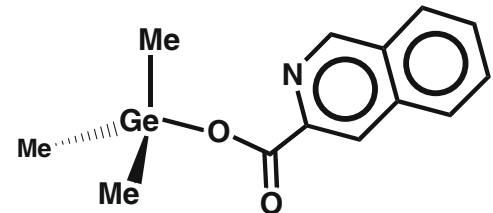

(2)
Scheme 1. Structures of organogermanium carboxylates.

In a typical experiment, an organogermanium carboxylate $(150 \mathrm{mg})$ was dissolved in dry benzene $(60 \mathrm{ml})$ in a twonecked round bottom flask, which was connected to a quartz tube placed in a horizontal tube furnace. An aerosol from this solution was generated at room temperature by use of ultrasonic humidifier. The aerosol was transported on to a pre-heated cleaned silicon wafer in a quartz tube by high purity argon flow maintaining a flow rate of $4 \mathrm{~L} / \mathrm{min}$. The substrate temperature was monitored by $\mathrm{Cr}-\mathrm{Al}$ thermocouple. The organic volatile part eliminated from the precursor and the solvent was carried by the argon flow and condensed in a liquid nitrogen trap placed at the end of the reactor. After cooling under argon flow, thin films were characterized by powder X-ray diffraction, EDS and SEM data.

Thermogravimetric analysis was performed on Netzsch STAPC Luxx instrument, which was calibrated with $\mathrm{CaC}_{2} \mathrm{O}_{4} \cdot \mathrm{H}_{2} \mathrm{O}$, with a heating rate of $10^{\circ} \mathrm{C} / \mathrm{min}$ under $\mathrm{N}_{2}$ atmosphere. Powder X-ray diffraction measurements were done on a Phillips PW 1810 instrument. Scan speed of XRD was $1.25^{\circ} \mathrm{min}$. Surface morphology was studied by scanning electron microscopy on a Kevex/Tescan Vega 2300T/40 instrument. EDS experiments were carried out on a Kevex Instrument. Current-voltage $(I-V)$ and capacitance-voltage $(C-V)$ measurements were carried out to evaluate electrical properties. For the electrical contacts, many gold dots ( $1 \mathrm{~mm}$ dia) were deposited on top of $\mathrm{Ge}$ and $\mathrm{GeO}_{2}$ films using shadow mask. For the $I-V$ and $C-V$ measurements of $\mathrm{Si} / \mathrm{Ge} / \mathrm{Au}$ and $\mathrm{Si} / \mathrm{GeO}_{2} / \mathrm{Au}$ structures, potentiostat PGSTAT 20 (Echochimie, The Netherlands), was used. Capacitance voltage characteristics of $\mathrm{Si} / \mathrm{GeO}_{2} / \mathrm{Au}$ structures were obtained from the impedance data measured using a peak-to-peak small signal a.c. voltage of $10 \mathrm{mV}$ at $100 \mathrm{kHz}$.

To prepare germanium oxide (germania) films, the germanium films were annealed under oxygen atmosphere in a furnace at $600^{\circ} \mathrm{C}$ for $3 \mathrm{~h}$. Films were characterized as $\mathrm{GeO}_{2}$ by powder X-ray diffraction, SEM and EDS data.

\section{Results and discussion}

Recently, we have described the synthesis of organogermanium carboxylates (Shah et al 2009). To evaluate the suitability of these complexes as molecular precursors for deposition of thin films of germanium, structurally characterized compounds, $\left[\mathrm{Et}_{2} \mathrm{Ge}\left(\mathrm{O}_{2} \mathrm{CC}_{5} \mathrm{H}_{4} \mathrm{~N}\right)_{2}\right]$ (1) and $\left[\mathrm{Me}_{3} \mathrm{Ge}\left(\mathrm{O}_{2} \mathrm{CC}_{9} \mathrm{H}_{6} \mathrm{~N}\right)\right]$ (2), were chosen as precursors. The precursors were crystallized and fully characterized ensuring their high purity. Their high solubility in dry organic solvents to serve as liquid germanium source, which is further converted into an aerosol (almost 100\%) by ultrasonic humidifier, allowed us to use them as precursor. Although these complexes are sensitive to moisture, they can be handled in air for a short period and hence ease of handling, which allows CVD experiments without extensive safety equipments. Thus, the use of these precursors is advantageous due to the ease of their preparation, purification, solubility and stability.

Thermogravimetric analysis of these compounds revealed nearly complete weight loss indicating their volatility. DTA curve of $\left[\mathrm{Et}_{2} \mathrm{Ge}\left(\mathrm{O}_{2} \mathrm{CC}_{5} \mathrm{H}_{4} \mathrm{~N}\right)_{2}\right]$ indicates that the first endotherm corresponding to melting of the compound is accompanied by nearly complete volatilization ( $\sim 98 \%$ weight loss). In the case of $\left[\mathrm{Me}_{3} \mathrm{Ge}\left(\mathrm{O}_{2} \mathrm{CC}_{9} \mathrm{H}_{6} \mathrm{~N}\right)\right]$, the first endotherm at $92^{\circ} \mathrm{C}$ corresponds to melting of the compound followed by a single step volatilization (figure 1). In an attempt to pyrolyze these compounds in a furnace at $300^{\circ} \mathrm{C}$ under an argon atmosphere, complete vaporization was noticed.

Aerosol assisted chemical vapour deposition (AACVD) of $\left[\mathrm{Et}_{2} \mathrm{Ge}\left(\mathrm{O}_{2} \mathrm{CC}_{5} \mathrm{H}_{4} \mathrm{~N}\right)_{2}\right](\mathbf{1})$ and $\left[\mathrm{Me}_{3} \mathrm{Ge}\left(\mathrm{O}_{2} \mathrm{CC}_{9} \mathrm{H}_{6} \mathrm{~N}\right)\right](\mathbf{2})$ at $700^{\circ} \mathrm{C}$ on boron-doped $p$-type silicon wafers resulted into germanium films. XRD patterns of the films obtained from these compounds were similar. XRD patterns were interpreted for the cubic phase with preferential orientation in (110), (220) and (311) planes (figure 2), which were in good agreement with the reported values for germanium (JCPDS

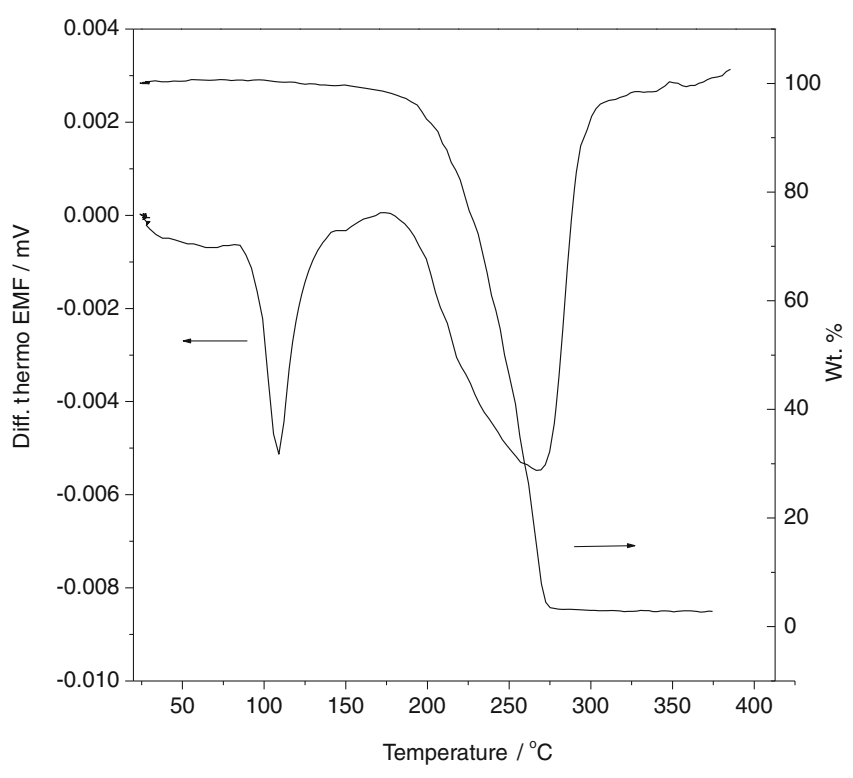

Figure 1. TGA curve of $\left[\mathrm{Me}_{3} \mathrm{Ge}\left(\mathrm{O}_{2} \mathrm{CC}_{9} \mathrm{H}_{6} \mathrm{~N}\right)\right]$. 


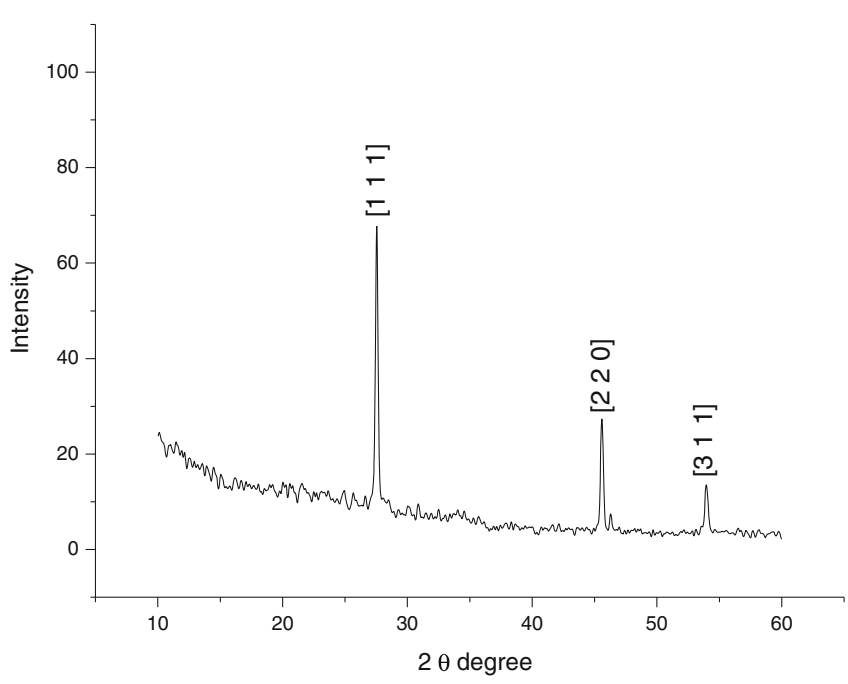

Figure 2. XRD pattern of $\mathrm{Ge}$ films obtained from $\left[\mathrm{Me}_{3} \mathrm{Ge}\left(\mathrm{O}_{2} \mathrm{CC}_{9} \mathrm{H}_{6} \mathrm{~N}\right)\right]$.

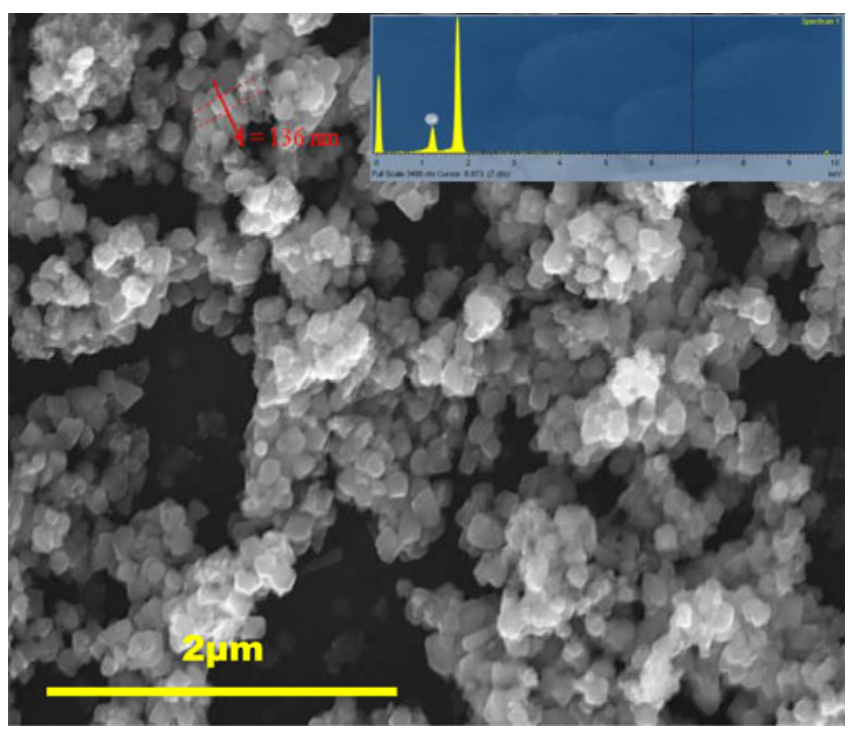

Figure 3. SEM image of $\mathrm{Ge}$ thin films obtained from $\left[\mathrm{Me}_{3} \mathrm{Ge}\left(\mathrm{O}_{2} \mathrm{CC}_{9} \mathrm{H}_{6} \mathrm{~N}\right)\right]$. Inset shows EDS spectrum of $\mathrm{Ge}$ thin film.

card\#:04-0545) (Kim et al 2003). The measured reflections were of high intensity with narrow peak widths indicating crystalline nature. The average size of germanium nanoparticles estimated by the Scherrer formula is $17 \mathrm{~nm}$ and $40 \mathrm{~nm}$ when precursors (1) and (2) are used, respectively. EDS analysis revealed deposition of germanium. No contamination species were observed within the sensitivity of the instrument. Scanning electron microscopic (SEM) images revealed agglomeration of germanium nanoparticles which were polygonal in shape (sizes: $<200 \mathrm{~nm}$ ) (figure 3). Germanium films prepared from other organometallic precursors, e.g. $\left[\mathrm{Me}_{3} \mathrm{Ge}(\mathrm{OEt})\right]$ by laser induced decomposition, yield germanium films contaminated with oxygen and carbon (Fajgar et al 1995). The films prepared from $\left[\mathrm{Cp} * \mathrm{GeH}_{3}\right]$ (Dittmar

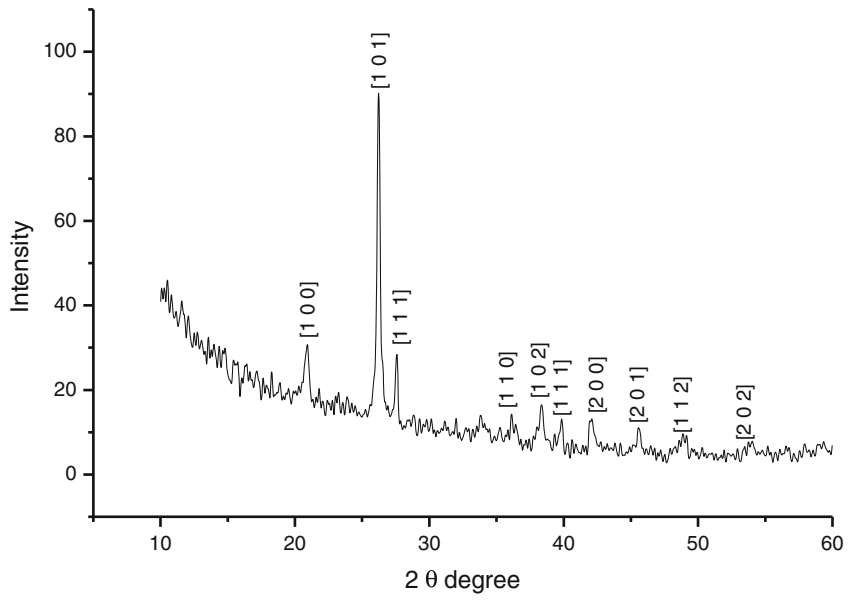

Figure 4. $\mathrm{XRD}$ pattern of $\mathrm{GeO}_{2}$ obtained by heating Ge film at $600^{\circ} \mathrm{C}$ in furnace under static oxygen.

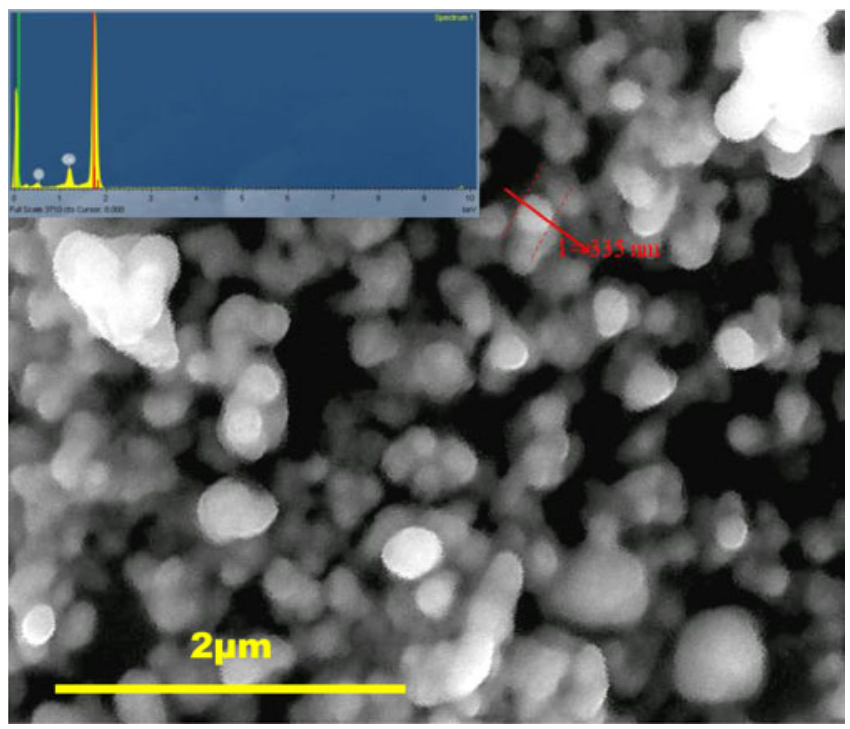

Figure 5. SEM of $\mathrm{GeO}_{2}$ thin films obtained by heating Ge film at $600^{\circ} \mathrm{C}$ in furnace under static oxygen. Inset shows EDS spectrum of $\mathrm{Ge}$ thin films oxidized to $\mathrm{GeO}_{2}$.

et al 2001) are contaminated with carbon (8\%) whereas $\mathrm{GeH}_{4}$ requires high decomposition temperature $\left(1250^{\circ} \mathrm{C}\right)$ (Mukherjee et al 2001).

The germanium films when heated at $600^{\circ} \mathrm{C}$ in a furnace under oxygen, lead to the formation of germanium oxide (germania) films. The selected reflections were indexed on the basis of hexagonal $\mathrm{GeO}_{2}$ and are marked in figure 4 . The unit cell parameters obtained from the observed data $[a=4.94$ (1) $\AA$ and $c=5.61$ (2) $\AA]$ are in good agreement with reported values for hexagonal $\mathrm{GeO}_{2}$ (JCPDS card\#:830544). A peak due to Ge (1 11 1) (JCPDS card\#:04-0545) was also found in $\mathrm{GeO}_{2}$ film indicating incomplete oxidation. However, quantitative analysis of $\mathrm{EDS}(\mathrm{Ge} / \mathrm{O}$ atomic ratio, 33.33:66.66, which is 1:2) confirmed the formation of 


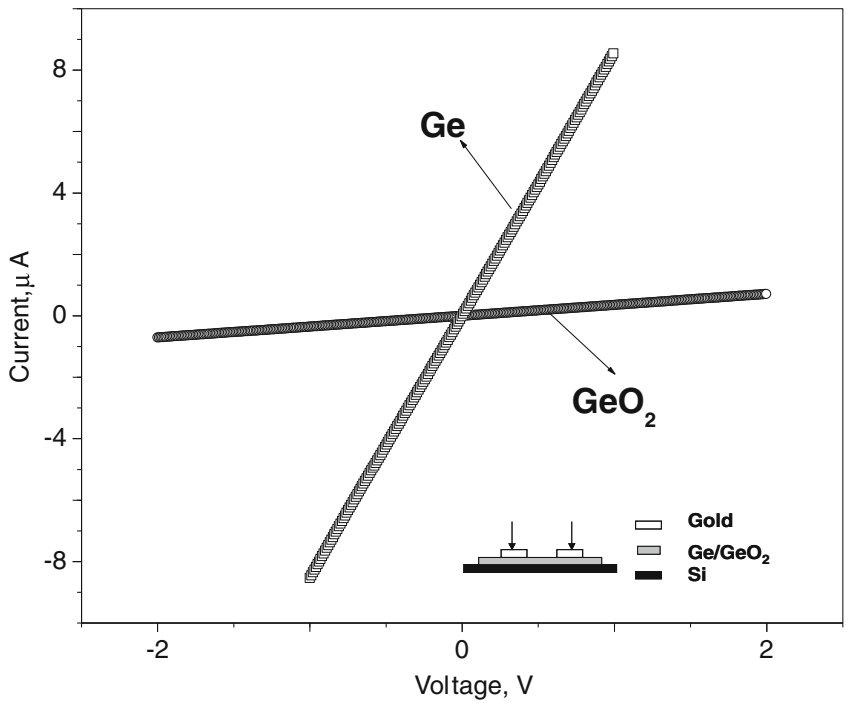

Figure 6. Typical $I-V$ characteristics of $\mathrm{Si} / \mathrm{Ge} / \mathrm{Au}$ and $\mathrm{Si} / \mathrm{GeO}_{2} / \mathrm{Au}$ co-planar structures. Inset shows schematic of co-planar structure.

germanium oxide. Oxidation of Ge films in an oxygen atmosphere has been described earlier (Ko et al 2008). A gradual oxidation of $\mathrm{Ge}$ to $\mathrm{GeO}_{2}$ with increasing annealing time has been reported earlier (Ko et al 2008). The average size estimated by Scherrer's formula of our $\mathrm{GeO}_{2}$ nanoparticles is $33 \mathrm{~nm}$. While comparing SEM images of $\mathrm{Ge}$ and $\mathrm{GeO}_{2}$ films, the former had well defined grain boundaries while the grain boundaries for the latter were diffused (figure 5).

Electrical properties of $\mathrm{Ge}$ and $\mathrm{GeO}_{2}$ have been studied by $I-V$ measurements. On a $\mathrm{Ge}$ or $\mathrm{GeO}_{2}$ film $(1 \times 1 \mathrm{~cm})$, many gold contacts (diameter, $\sim 1 \mathrm{~mm}$ ) separated by $2 \mathrm{~mm}$ were deposited on the growth side. $I-V$ characteristics of both the structures, $\mathrm{Si} / \mathrm{Ge} / \mathrm{Au}$ and $\mathrm{Si} / \mathrm{GeO}_{2} / \mathrm{Au}$, were carried out using co-planar structure between various pairs of adjacent gold dots on the same film. These measurements showed ohmic behaviour for both $\mathrm{Ge}$ and $\mathrm{GeO}_{2}$ films (figure 6). The resistivity values calculated for $\mathrm{Ge}$ and $\mathrm{GeO}_{2}$ films were $1.44 \mathrm{k} \Omega-\mathrm{cm}$ and $35.6 \mathrm{k} \Omega-\mathrm{cm}$, respectively. Capacitance voltage studies of $\mathrm{Si} / \mathrm{GeO}_{2} / \mathrm{Au}$ structures (not shown) gave constant capacitance of $1.28 \mathrm{pF}$ indicating the characteristics of a typical insulator.

\section{Conclusions}

Germanium thin films have been deposited by AACVD using di- and tri-organogermanium carboxylates. These films can be oxidized to germania using conventional heating in oxygen ambient. Ge and $\mathrm{GeO}_{2}$ films have been characterized by various techniques. It has been demonstrated that high quality $\mathrm{Ge}$ and $\mathrm{GeO}_{2}$ films can be obtained conveniently by using organogermanium carboxylates.

\section{References}

Boucham J E, Maury F and Morancho R 1998 J. Anal. Appl. Pyrol. 44153

Dittmar K, Jutzi P, Schmalhorst J and Reiss G 2001 Chem. Vap. Dep. 7193

Fajgar R, Bastl Z, Tlaskal J and Pola J 1995 J. Appl. Organomet. Chem. 9667

Henderson E J, Hessel C M, Cavell R G and Veinot J G C 2010 Chem. Mater. 222653

Kim H Y, Viswanathamurthi P, Bhattarai N and Lee D R 2003 Rev. Adv. Mater. Sci. 5220

Ko T S, Shieh J, Yang M C, Lu T C, Kuo H C and Wang S C 2008 Thin Solid Films 5162934

Kohlhase A, Cheng M -L, Kobayashi S, Murota J and Mikoshiba N 1991 Vacuum 42269

Liu P, Cui H, Wang C X and Wang G W 2010 Phys. Chem. Chem. Phys. 123942

Mukherjee C, Seitz H and Schröder B 2001 Appl. Phys. Lett. 78 3457

Pola J, Fajgar R, Bastl Z and Diaz L 1992a J. Mater. Chem. 2961

Pola J, Parsons J P and Taylor R 1992b J. Chem. Soc. Faraday Trans. 881637

Shah A Y, Wadawale A, Sagoria V S, Jain V K, Sharma R, Nagar M and Bohra R 2009 Indian J. Chem. A49 333

Shah A Y et al 2010 Inorg. Chim. Acta $\mathbf{3 6 3} 3680$

Sze S M 1981 Physics of semiconductor devices (New York: Wiley)

Trukhin A N 2009 J. Non-Cryst. Solids 3551013

Veprek S, Prokop J, Glatz F, Merica R, Klingan F R and Herrmann W A 1996 Chem. Mater. 8825

Wang D, Chang Y, Wang Q, Cao J, Farmer D B, Gordon R G and Dai H 2004 J. Am. Chem. Soc. 12611602

Woelk E, Shenai-Khatkhate D V, DiCarlo Jr. R L, Amamchyan A, Power M B, Lamare B, Beaudoin G and Sagnes I 2006 J. Cryst. Growth 287684

Zacharias M and Fauchet P M 1998 J. Non-Cryst. Solids 227-230 1058 